\title{
Lettering and Signage in the Urban Environment of North Queensland's Capital: Tropical Flair or Univernacular?
}

\author{
Katja Fleischmann \\ James Cook University
}

\begin{abstract}
Many typefaces possess next to stylistic qualities also cultural and connotative properties. This paper describes an exploration of signage and lettering in the capital of North Queensland in the quest for a tropical typographic resonance. Is the vernacular typography alive or a vanishing art form?
\end{abstract}

\footnotetext{
A young designer recently posted a request for help on a graphic design blog: "I have to do a piece for the tropics... Can anybody recommend a typeface?” Replies to his request were sparse and mostly pointing toward websites with typefaces of varying quality available for free by download. These fonts were predominantly decorative in style, featuring a palm tree or leaf intertwining with a letter. Few of the recommendations could be considered to truly connote the tropics.
}

This exchange begs the question: is there even such thing as a typeface signifying the tropics? Is there type, lettering or signage that could be said to communicate the qualities of the tropics, or creates a corresponding sense of place? More specifically, is there a unique typographic landscape created through signage and lettering in the urban environment of Townsville, the capital of tropical North Queensland? In search of a distinctive vernacular typography, the author wandered the streets of the city, investigating type in both obvious and hidden places, discovering writing on forgotten walls and inspecting signage of business owners advertising their services.

\section{More than just letters}

A letter, in itself, has no semantic meaning; it is a visual stand-in for a speech sound. It "denotes one thing-its sound-until its connotative power is extended and intensified by the designer" (Meggs 122). Extending this connotative power is achieved by designers through the use of typography. "Typography is the art and technique of creating and composing type in order to convey a message. The term 'type' includes the design and function of alphabetic and analphabetic symbols to represent language” (Woolmann and Belantoni 7).

Since the beginning of the digital age, many thousands of different typefaces have become readily available, and new typefaces are constantly under development (Adams 39). Choosing a typeface for a design can therefore be a challenging task for a designer, particularly when knowing that it "is one of the most influential elements that establishes the character and emotional attributes of a design" (Ambrose and Harris, Fundamentals of Graphic Design 38). This is due to the fact that typefaces have a dual life (Meggs 120); next to their plain duty of conveying written information (the utilitarian), they have particular visual and aesthetic 
properties (the formal) (Ruder 14). These properties "dramatically affect the accessibility of an idea and how a reader reacts towards it" (Ambrose and Harris, Fundamentals of Graphic Design 38). They establish a resonance in the reader, which can be either inviting or repelling (Meggs 18). "The visual nature of typography is extraordinary for it can combine the timespace sequence and rhythm of music, the linear structure of language, and the dynamic space of painting” (Meggs 18). A typeface has its own personality which can infuse text appearing on a screen, a poster or a wall (Ambrose and Harris, Fundamentals of Typography, 162). The artistic representation or interpretation of characters can thereby intensify or contradict the meaning of words. This relationship between aesthetic form and semantic content is demonstrated by the example shown in Figure 1.

(a)

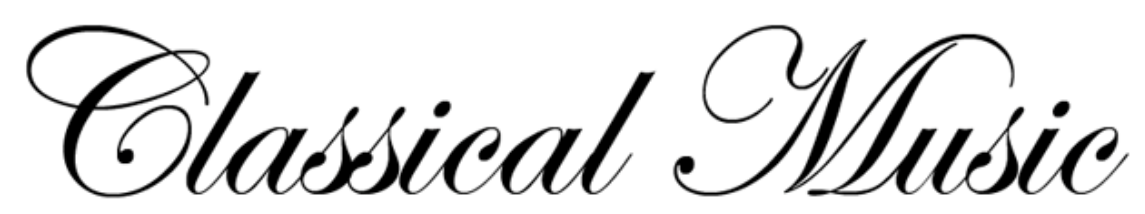

(b)
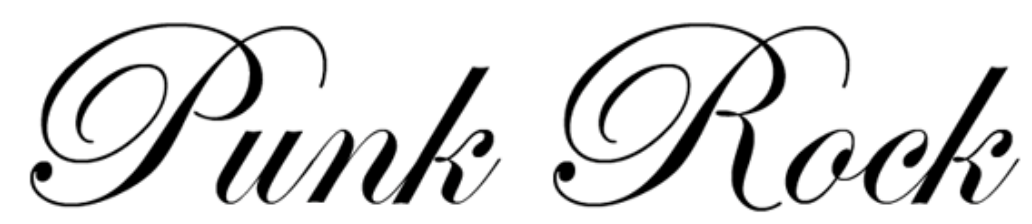

Figure 1: The elegant flow of harmonious and fluid lines which characterizes the typeface ITC Edwardian Script intensifies the meaning of word (a) whereas in (b) the same typeface undermines the meaning and may confuse or disturb the reader.

\section{Typeface as signifier of national and social identity}

Typographic resonance can also be "generated by the cultural, stylistic, and connotative properties that typefaces possess in addition to their function as alphabet signs” (Meggs 120). A typeface accumulates these resonant qualities through associations relating to its typical use, historical tradition, and its visual properties (Meggs 120). A classic example is provided by the typeface Fraktur, shown in Figure 2.

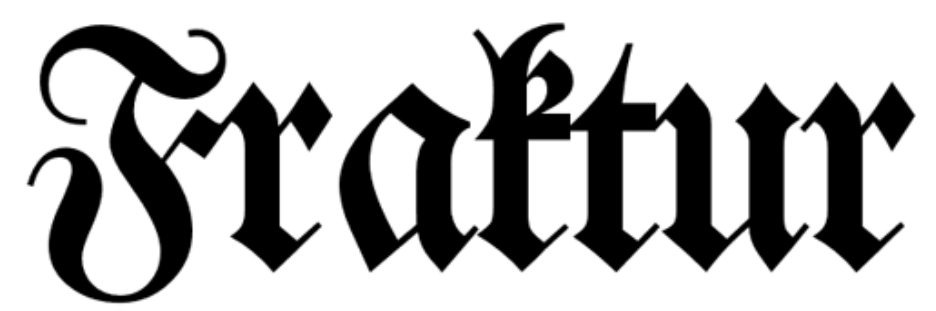

Figure 2: Typeface Fraktur

Fraktur, which belongs to the class of blackletter typefaces, has been closely associated with German national identity. It name is derived from the strong contrast between thin and thick strokes and the sharp angles, giving the letters a fractured look. "After the invention of 
Gutenberg's moveable type in the 15th century, black letter became an embodiment of Germanness and a focus of Teutonic pride" (Wise). Fraktur was used in the Third Reich until 1941 (Haralambous 131, Schalansky 7) and proclaimed by the Nazis as the only "true German type" (Siebert). As a result of this appropriation the typeface became associated with the horrors of National Socialism (Willberg 41). Today Fraktur is tolerated by Germans only in folklore or historical context and may be seen on beer labels (Willberg 42) or in rare survivals like the masthead of the Frankfurter Allgemeine Zeitung "suggesting conservative or traditional values” (Schwemer-Scheddin 57).

Fraktur also provides a good illustration of how the choice of typeface can "contextualise the socio-cultural affiliation of a text," what Androuslopoulos (381) calls the 'emblematic' aspect of a typeface. According to Androuslopoulos, typography is a situated code choice "which is always part of a specific genre in a specific communicative situation," that is, an expression of social identity (381). Indeed blackletters, with their rich and varied history (Reynolds), experienced a revival when they re-emerged through their use in music-related subcultures such as Hip Hop (Figure 3). Other typefaces, such as Template Gothic, designed by Berry Deck in 1990, are typically associated with Punk Rock or Grunge, with their DIY aesthetic elements (Triggs 69). "In late modernity, all music-related subcultures use typography as a resource for the creation and propagation of an aesthetic identity” (Androuslopoulos 382).

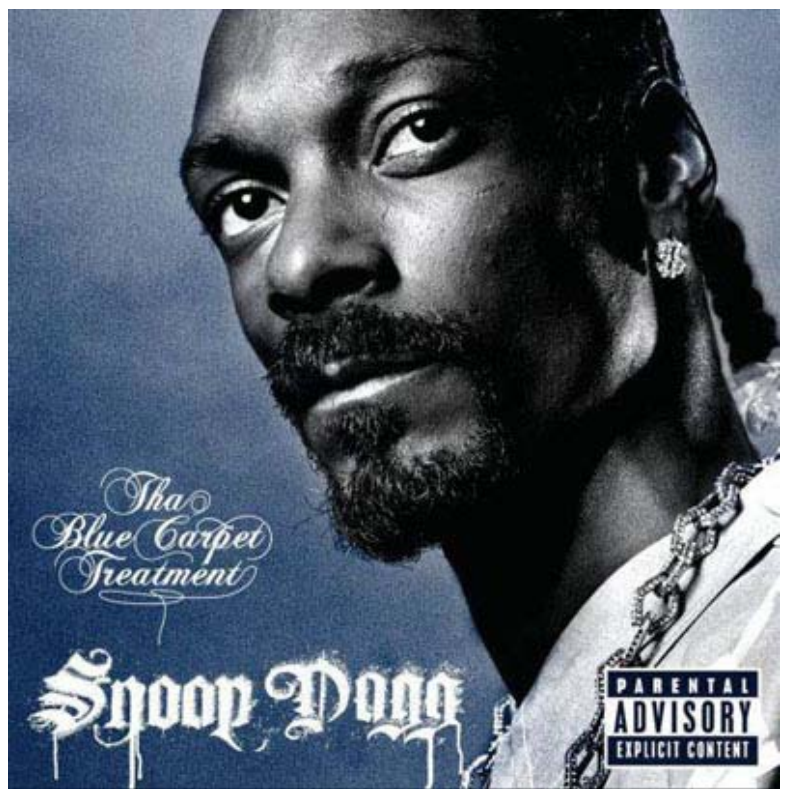

Figure 3: CD Cover “Tha Blue Carpet Treatment” by rapper Snoop Dogg

Although blackletters entered the mainstream through "English and American pop- and subcultures import[ing] music- and lifestyles and their accompanying typography" (Schwemer-Scheddin 64), it is crucial to be aware of their history. Knowing the connotative power of typefaces is critical (Ambrose and Harris, Fundamentals of Graphic Design 70). The designer must remain alert to the larger historical context in which typefaces are embedded. To take the obvious example: unwary use of Fraktur or similar blackletter type may add a wholly unintended layer of meaning.

\section{Sense of place: A tropical typeface?}


Cultural, stylistic, and connotative properties that typefaces possess can also contribute to creating a sense of place. When travelling to a foreign country, the feelings or perceptions held by people in regards to the place are created through architecture, vegetation, light, smells, foods or people's clothing. Typography encountered on the scene, such as street signs, shop signage and other environmental graphics, can all contribute to the formation of a sense of place. Conventionally, 'the tropics' as a place are commonly associated with palm trees, white sandy beaches, turquoise blue water and bright sunlight. However, is there such a thing as a typeface that depicts the tropics, or one that would be associated with the tropics?

Typefaces can indeed "visually reflect very closely the time and place in which they were made" (Antonelli). One well-known example of a 'tropical' typeface is the family of eight island-inspired Tiki Type fonts created by the type foundry House Industries. The designs for Tiki Hut, Tiki Wood and Tiki Palms, for example, were influenced by the place, history and culture of the Polynesian islands (Borden). Another typeface is the ITC Puamana, designed by Teri Kahan, which is described as capturing "the essence of the tropics, suggesting palm trees bending in an ocean breeze” (Haley 1) (Figure 4).
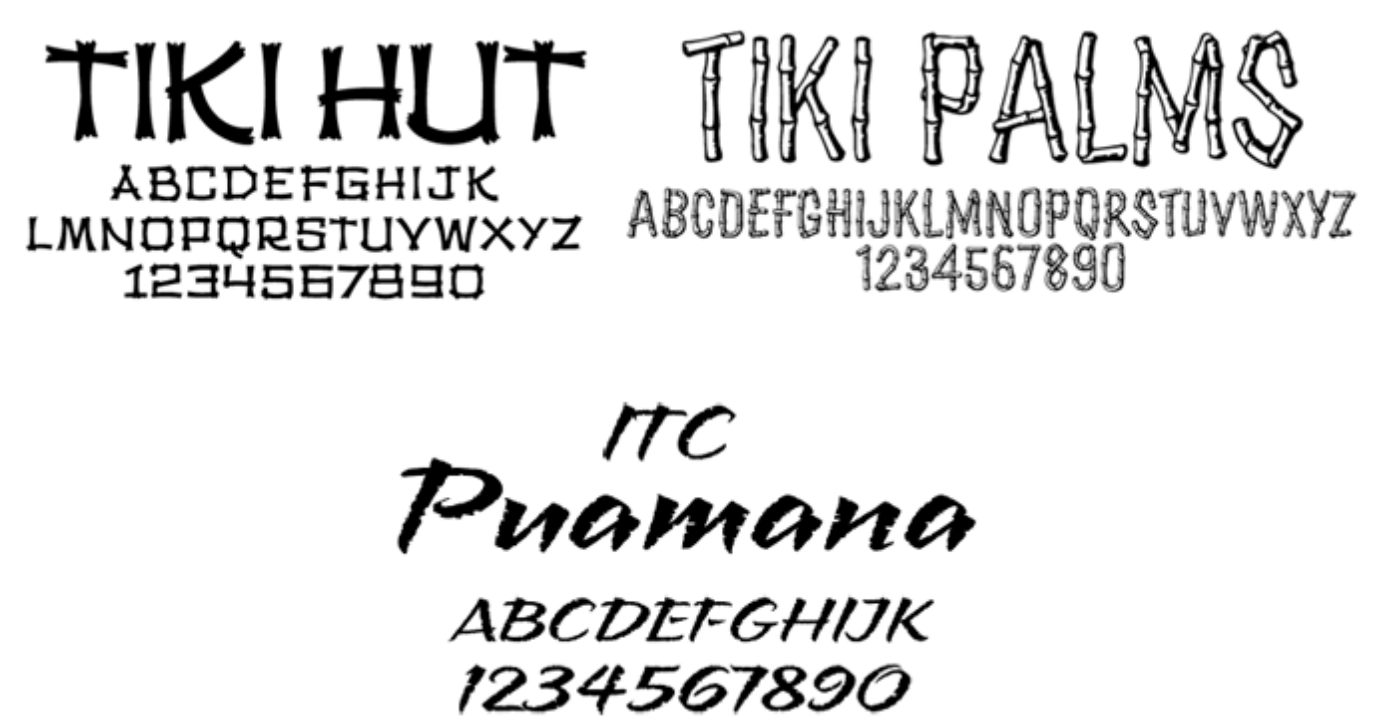

Figure 4: Typefaces Tiki Hut, Tiki Palms and ITC Puamana

Those who have visited Hawaii, for example, will attest that the lettering and signage to be seen on shops, cafes and restaurants often has a distinct 'look and feel'. In fact, encounters with Tiki and Puamana are frequent, thus becoming a part of the creation of a sense of place (Figure 5). 


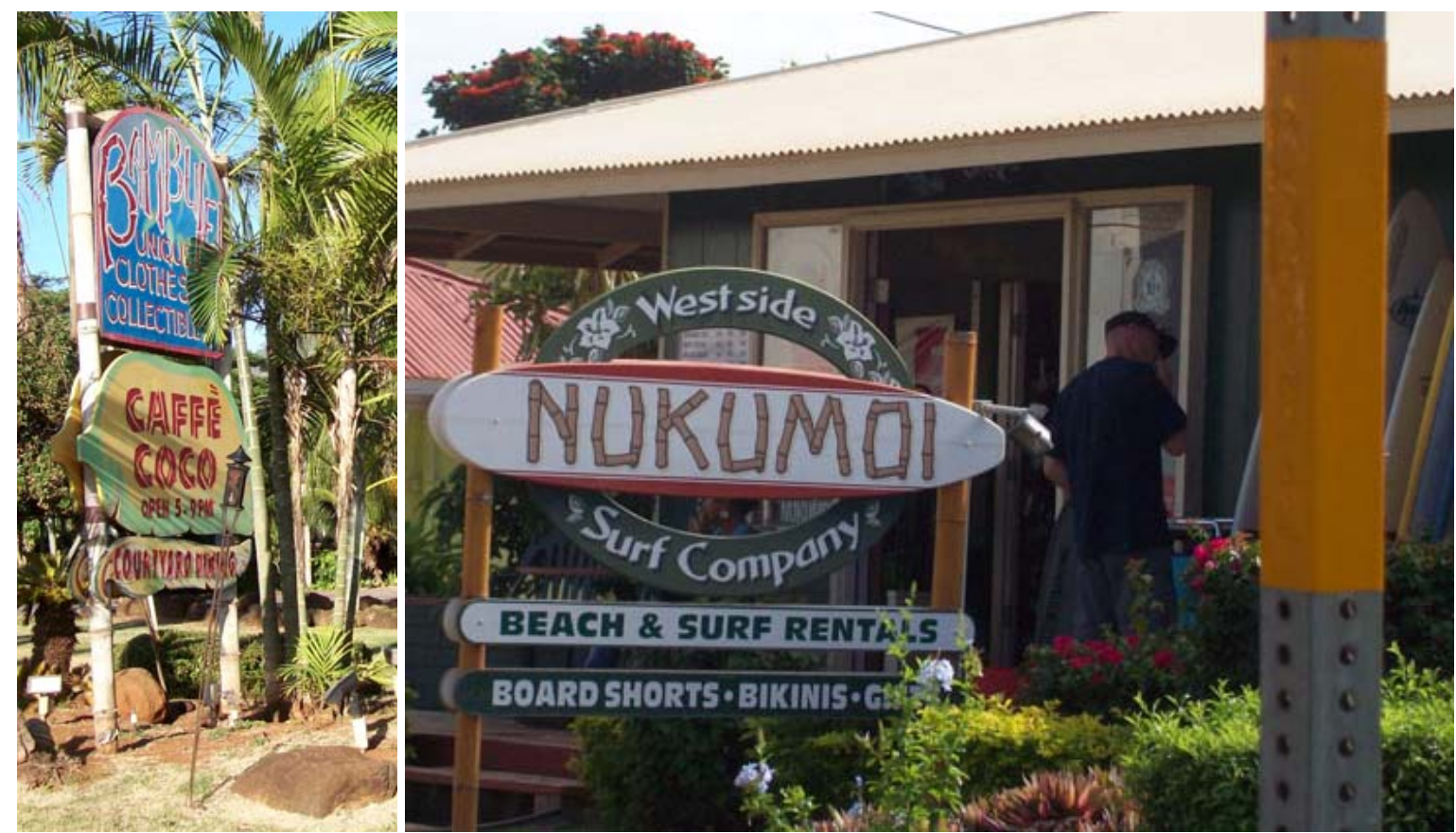

Figure 5: Signage in Hawaii. Tiki Palms is used for signage of a surf shop (right). 


\section{The typographic landscape in Townsville}

Townsville, the capital of North Queensland is located in the dry tropics region. "Less than two hours by plane from Brisbane, Townsville is a vibrant growing city with a diversified economy. Solid growth in the mining, defence, construction and tourism industries are driving economic growth in Townsville. Townsville provides the commercial, industrial and transportation hub for the region and is the largest city in northern Australia” (Queensland Government).

In search for Townsville's typographic identity, made up of signage and lettering on walls, shops and other environmental signage, Townsville appears shy at first sight in advertising its tropical location. In contrast to Hawaii, distinct tropical typefaces such as the Tiki fonts or ITC Puamana are absent from the lettering and signage landscape in Townsville. However, it is not difficult to turn up signage with figurative elements including palm trees, the sun, or ocean wave, giving away its location (Figure 6).

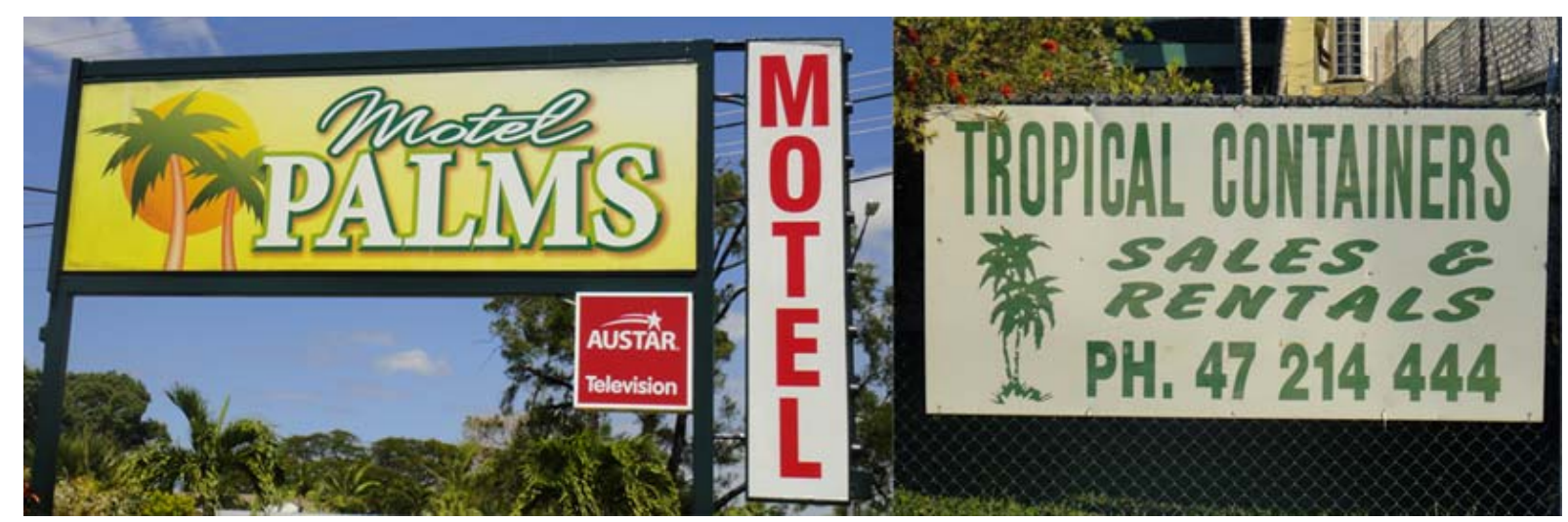

Figure 6: Signage with figurative elements

A further indication of the city's tropical location is provided by distinctive local handlettering techniques, characterised by bold, bulging letterforms and bright colours that provide cognitive hooks. These often feature yellowish-white lettering framed by dark outlines representing the shadows that would be cast by the tropical sun if these two-dimensional letters were indeed three-dimensional constructions (Figure 7). 


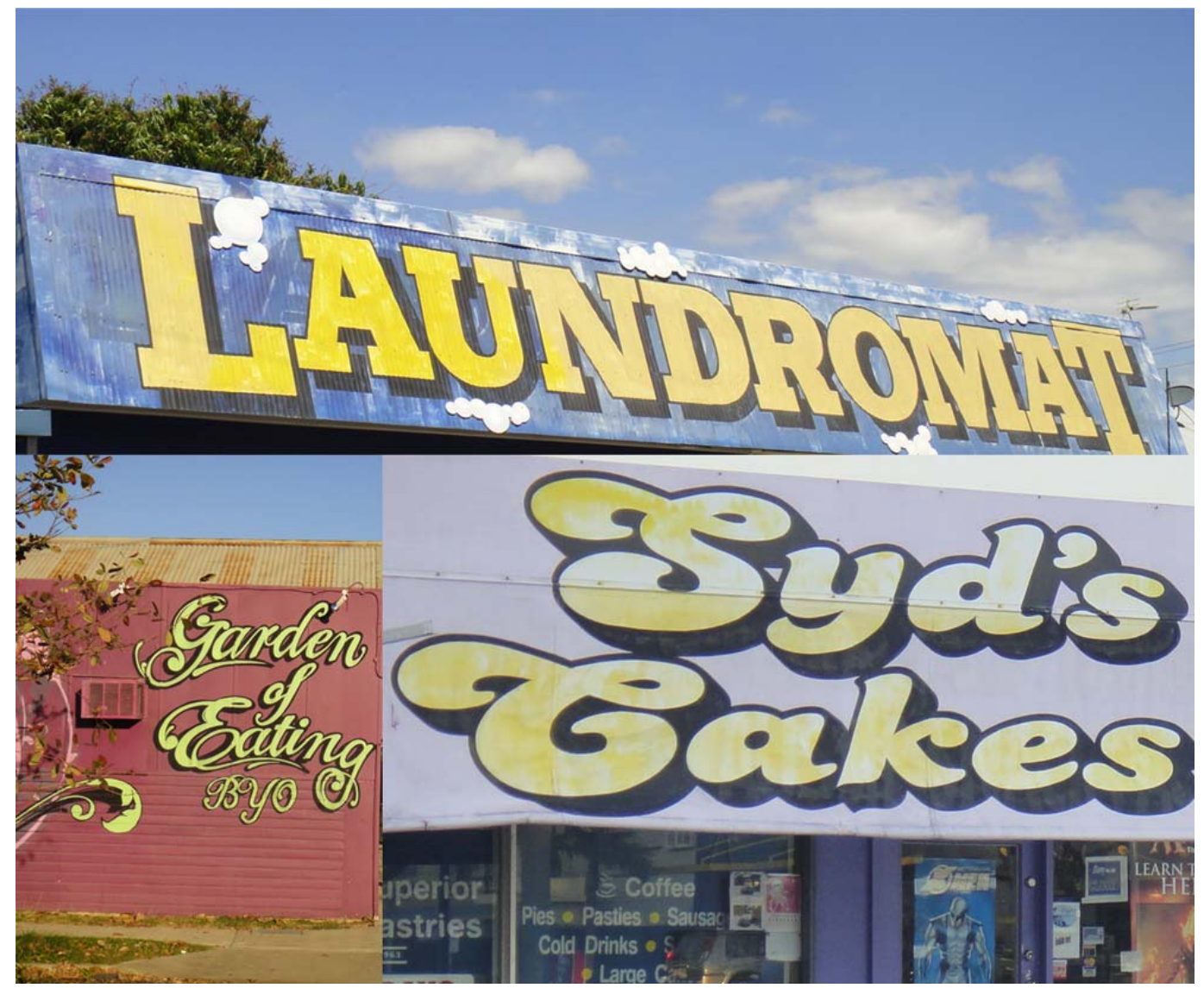

Figure 7: Typical hand-lettering

Uniqueness, however, is predominantly created through the faded, the scratched and weathered, or otherwise worn-out aspects of the lettering written on the walls and shop fronts. Townsville's signage clearly shows its geographical location, be it as a result of the many hours of daily sunshine taking its toll on the painted signage (Figure 8), or through such events as cyclones. One such event was Yasi, in early 2011, which left its traces on some of the signage (Figure 9). 


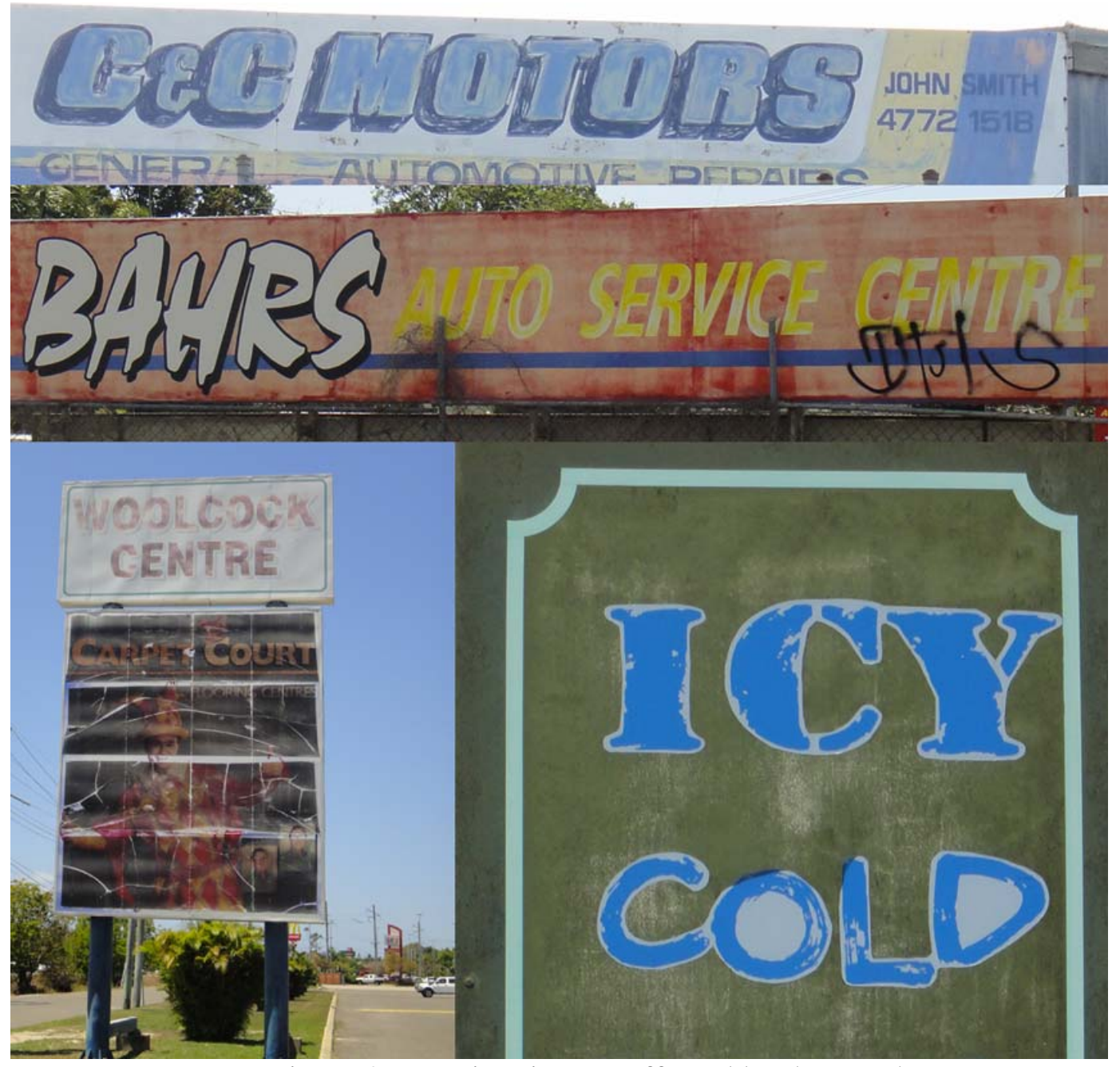

Figure 8: Exterior signage affected by the weather

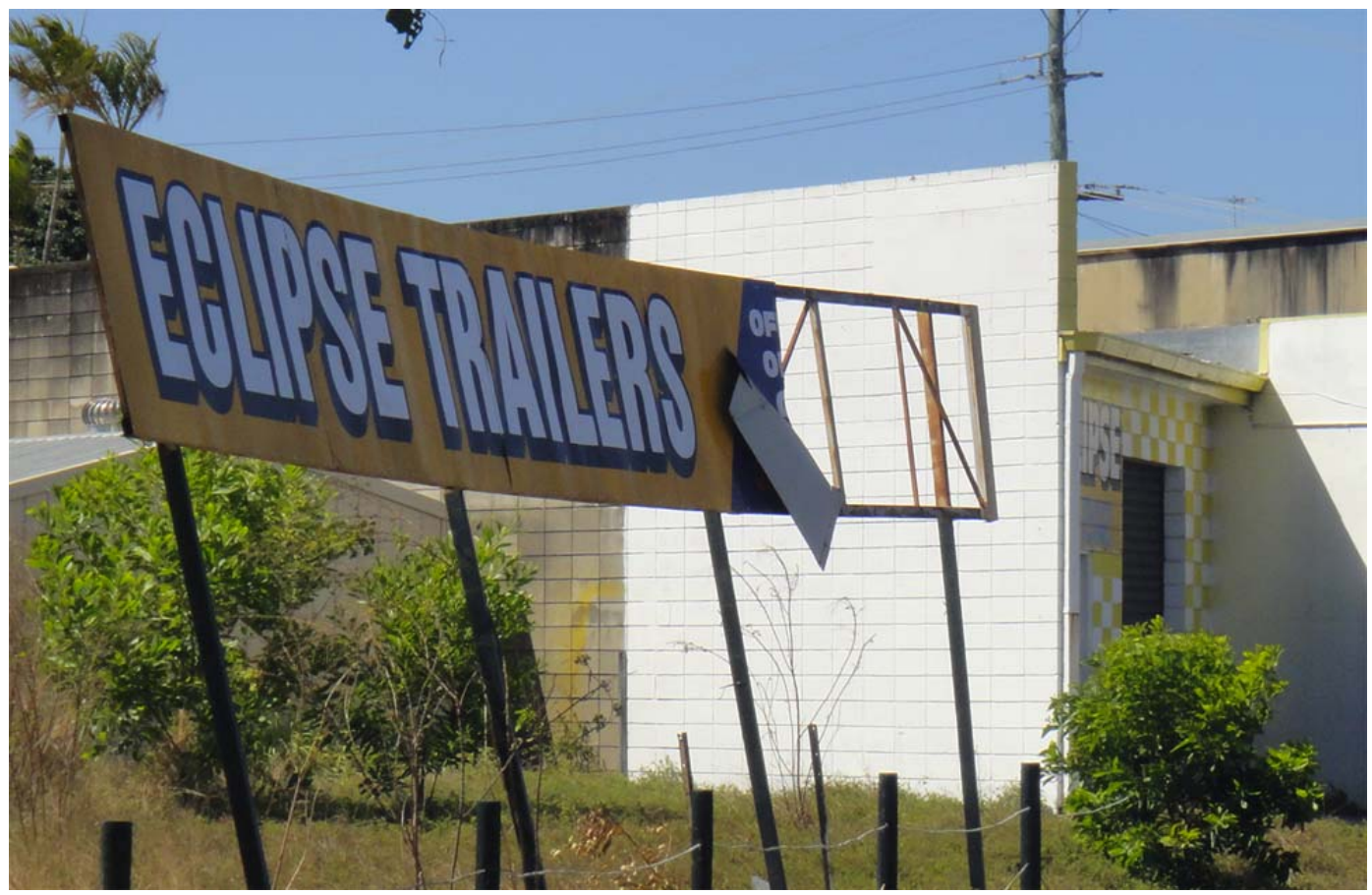

Figure 9: Climatic event left its trace 
Similar to the effects of weathering are the visible traces of 'change' evident in a number of signboards on Townsville's shop fronts and business entrances. Old ownerships were crudely overpainted or perhaps professionally oversprayed but have simply failed to withstand the assaults of the weather. These visual reminders "denoting the physical passage of time" (Helfand 44) provide a document of local history, forming an essential part of the charm of Townsville’s signage (Figure 10).

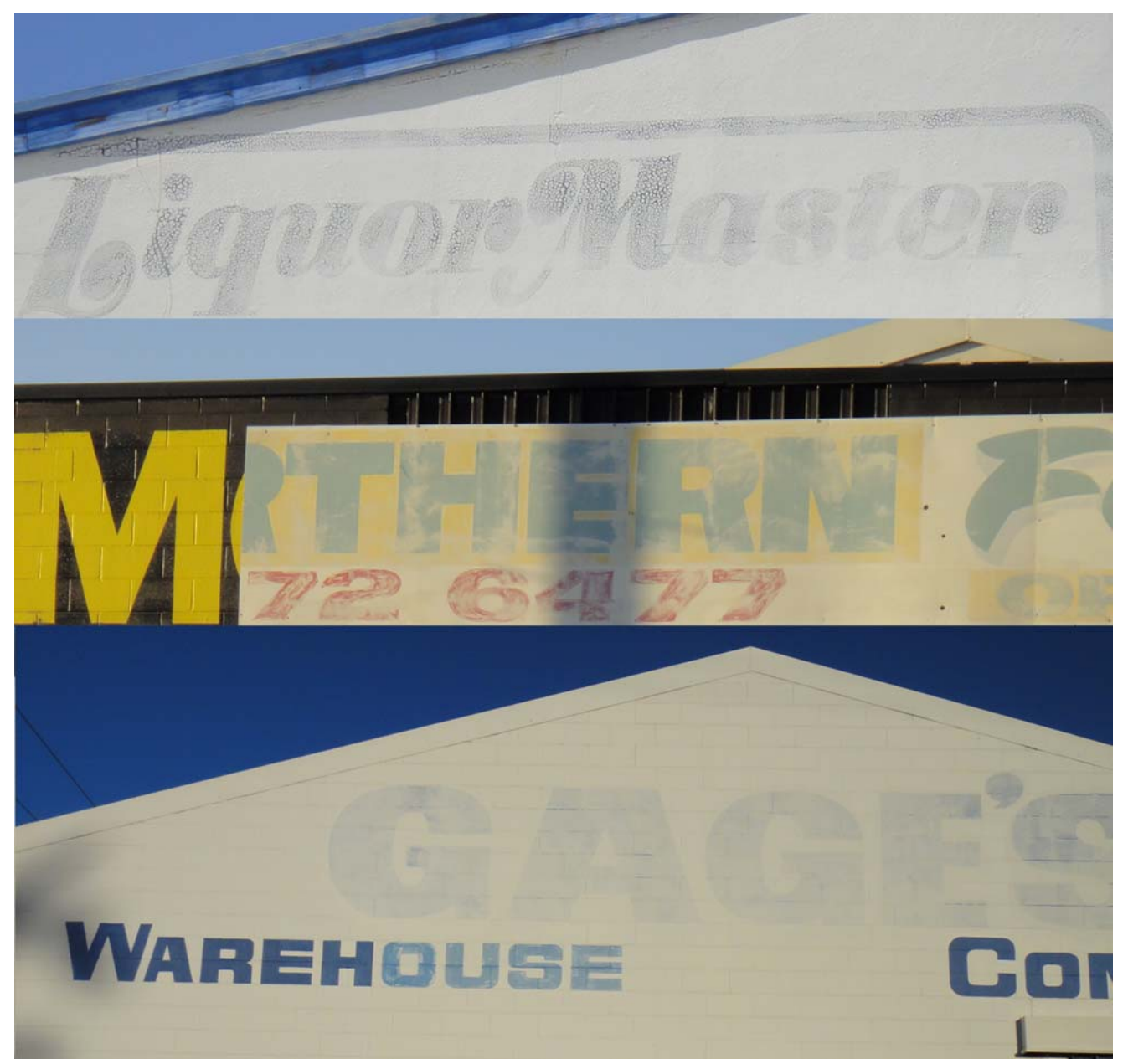

Figure 10: Traces of change

\section{Tropical flair vs. univernacular}

While examples like those described above remain plentiful around Townsville, it is also evident that some of the city's lettering and signage are not just fading but actually disappearing (Figure 11). 


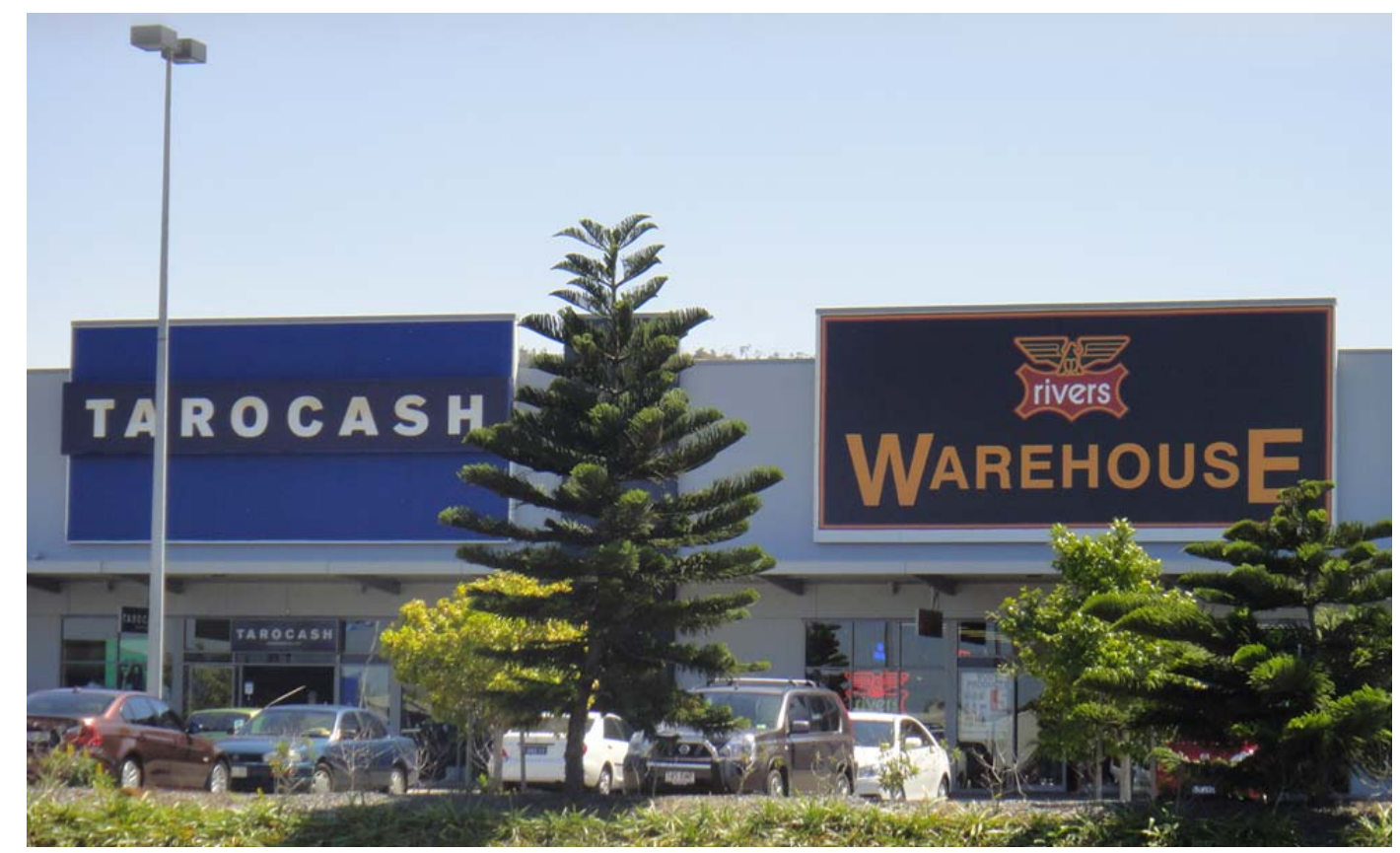

Figure 11: Shopping complex in Townsville

Townsville is similar to other growing cities worldwide, and, as such, Sprowl is unambiguous about its fate: "Globalization will take care and melt away any specific features within them before long”.

Indeed, 'bigger and better' signage has long adorned Townsville's shopping malls, gas stations and franchise coffee shops, evidence of the successful implementation of a corporate design strategy at a national and/or international level - and including the use of corporate typefaces. Describing the promise of a new economy, Helfand notes “...distinction is passé. Conformity rocks. ... How nice that we can sleep soundly knowing there is a place for everything, and everything is in place. After all, everything looks and feels so much like everything else!”(45) While 'sameness' may be comforting, part of a unique regional identity is in danger of being lost. (Figure 12) 
a)

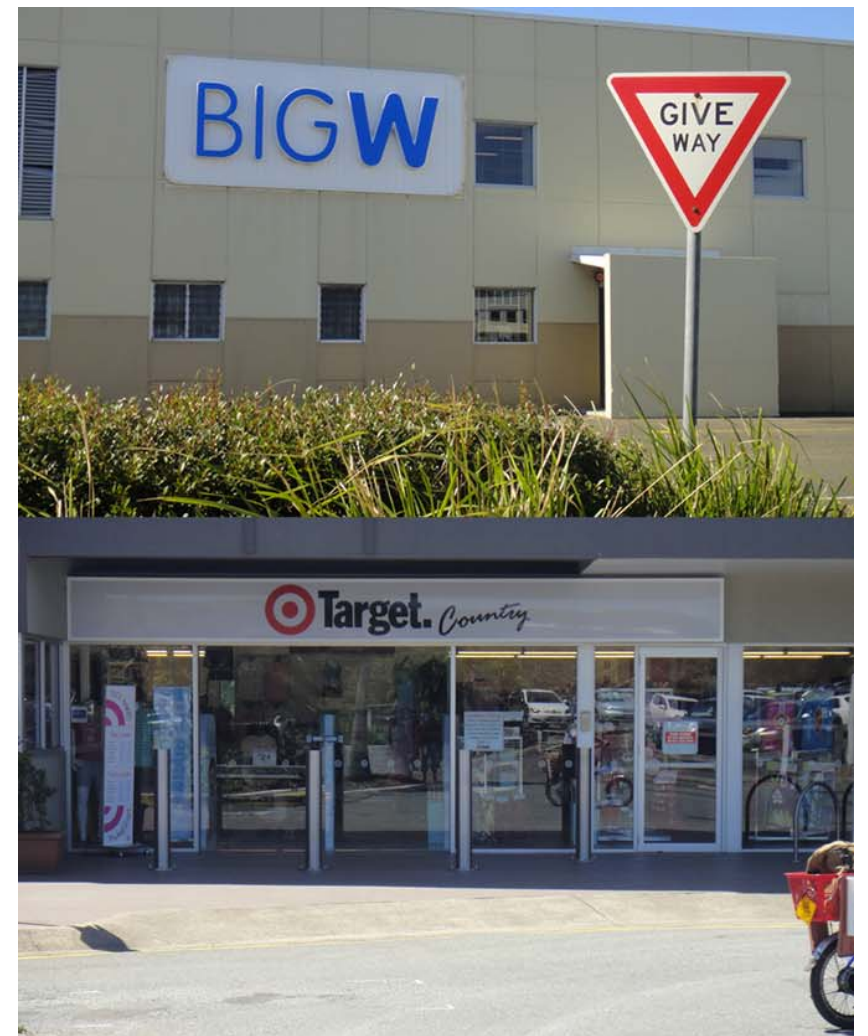

c)

b)

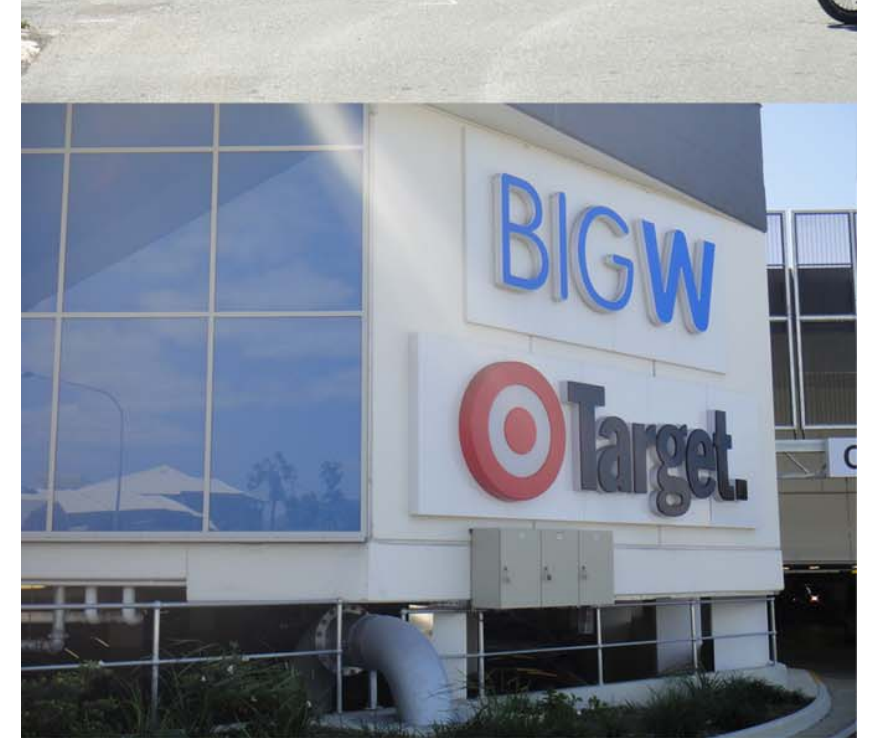

Figure 12: Where is this place? Department stores in (a) Kawana Waters at the Sunshine Coast (distance to Townsville 1280km), (b) Noosa (1020km), (c) Townsville

How to preserve Townsville's distinct sense of place? A fusion of past and the present might be created, designed to keep parts of Townsville's regional identity alive and so preserve a unique 'tropical flair' based on local history and tradition. It is time to take care of some of Townsville's unique vernacular signage, to archive it and maybe re-use it, maybe to create Townsville’s very own tropical typeface. 


\section{Works Cited}

Adams, Sean. “Typographic Education in a Digital Environment.” Education of an E Designer. Ed. Steven Heller. New York: Allworth Press, 2001. 38-41. Print.

Ambrose, Gavin and Paul Harris. Fundamentals of Typography. Lausanne: Ava Publishing, 2007. Print.

Ambrose, Gavin and Paul Harris. The Fundamentals of Graphic Design. Lausanne: Ava Publishing, 2008. Print.

Androutsopoulos, Jannis. “Typography as a resource of media style: cases from music youth culture.” Proceedings of the 1st International Conference on Typography and Visual Communication. Ed. Klimis Mastoridis. Thessaloniki: University of Macedonia Press, 2004. 381-392. Print.

Antonelli, Paola. “Emigre Typefaces Enter MoMA Design Collection. “Emigre News.” Mar. 2011. Web. 10 Nov. 2011.

Borden, Mark. “The Masters of Typography: House Industries.” Fastcompanies. 1 Oct. 2008. Web. 12 Nov. 2011.

Haley, Allan. “Five New Typefaces.” DESIGNERS Step Inside Design - Step Online. Nov/Dec 2005, 1-3. Web. 11 Nov. 2011.

Haralambous, Yannis. “Typesetting Old German: Fraktur, Schwabacher, Gotisch and Initials.” TEX 90: Conference proceedings, University College, Cork, Ireland, September 10-13, 1990; TEX Users Group, 1991. 129-138. Print.

Helfand, Jessica. "Modern Life and the Univernacular.” Jessica Hefand Screen: essays on graphic design, new media, and visual culture. New York: Princeton Architectural Press, 2001. 41-46. Print.

Meggs, Philip B. Type and Image: The Language of Graphic Design. Wiley, 1992. Print.

Queensland Government. “Townsville region.” Skilled and Business Migration. 14 May 2009. Web. 11 Nov 2011.

Ruder, Emil. Typography: A Manual of Design. 6th edition. Sulgen: Verlag Niggli AG, 1996. Print.

Schalansky, Judith. Fraktur Mon Amour. New York: Princeton Architectural Press, 2008. Print.

Schwemer-Scheddin, Yvonne. "Broken Images: Blackletters between Faith and Mysticism.” Blackletter: Type and National Identity. Eds. Peter Bain and Paul Shaw. New York: Princeton Architectural Press, 1998. 50-67. Print. 
Siebert, Jürgen. “Fraktur ist (auch) eine Nazi-Schrift.” Fontblog. 14 Oct. 2006. Web. 12 Nov. 2011.

Sprowl, T, “What makes a typeface unique to a nation or culture?” Typophile. 8 Jan. 2003. Web. 12 Nov. 2011.

Staples, Loretta. “Typography \& the Screen: A Technical Chronology of Digital Typography, 1984-1997.” Design Issues 16.3 Autumn 2000: 19-34. Print.

Triggs, Teal. "Scissors and Glue: Punk Fanzines and the Creation of a DIY Aesthetic." Journal of Design History 19.1 (2006): 69-83. Print.

Willberg, Hans Peter. "Fraktur and Nationalism.” Blackletter: Type and National Identity. Eds. Peter Bain and Paul Shaw. New York: Princeton Architectural Press, 1998. 4049. Print.

Wise, Micheal Z. “A Typeface as Symbol of National Pride.” New York Times 1 Mar. 1998. Print.

Woolman, Matt and Bellantoni, Jeff. Moving type: designing for time and space. Amsterdam: BIS Publishers, 2000. Print. 